ARTÍCULOS 



\section{ACERCA DEL OPTIMISMO. LEIBNIZ Y LA TESIS DE LA ARMONIIA UNIVERSAL}

Cristina Alayza

Pontificia Universidad Católica del Perú

calayza@pucp.edu.pe

Este ensayo busca evaluar la optimista afirmación de Leibniz según la cual el nuestro es el "mejor de los mundos posibles". Para ello, se intenta leerla a la luz del contexto original del cual se extrae dicha frase, es decir, adentrarse aunque sea brevemente en el sistema que Leibniz formuló para rastrear los motivos que lo llevaron a expresarse de ese modo. En suma, se intenta comprender no solo el sentido de dicha frase, sino (en contra de Voltaire quizá) al propio Leibniz, o en todo caso, a su optimismo. Con eso en mente, primero se plantea la tesis leibniziana de la multiplicidad de mundos posibles (§I), para preguntarse luego por qué, de entre ellos, nuestro mundo habría de ser el mejor, lo cual conduce a examinar el principio de razón suficiente (\$2). Al hacerlo aparece inevitablemente el tema de Dios, lo cual motiva a su vez la pregunta de por qué Dios eligió crear este mundo en particular en vez de otro (§3). Finalmente se vincula la armonía preestablecida con el optimismo.

Palabras clave:

Leibniz, optimismo, armonía universal, mundos posibles 
No pasa un día sin que usemos la palabra optimismo, que fue acuñada por Voltaire contra Leibniz, que había demostrado (a despecho del Eclesiastés y con el beneplácito de la Iglesia) que vivimos en el mejor de los mundos posibles. Voltaire, muy razonablemente, negó esta exorbitante opinión. (En buena lógica, bastaría una sola pesadilla o un solo cáncer para anularla). Leibniz pudo haber replicado que un mundo que nos ha regalado a Voltaire tiene algún derecho a que se le considere el mejor.

JORGE LUIS BORGES

En 1767 Voltaire terminaba de escribir un cuento que llevaría por título "Cándido o el optimismo". El cuento narra la historia de Cándido, joven oriundo de Westfalia al que le suceden las mayores desgracias, imaginables e inimaginables también. Sin embargo Cándido ha aprendido bien las lecciones de su maestro Pangloss, y sabe que no hay efecto sin causa y que en este mundo, el mejor que podemos imaginar, todo ocurre por algo y de acuerdo a una finalidad mayor, de modo que, a fin de cuentas, no hay nada de qué realmente lamentarse. De esta manera se burlaba abiertamente Voltaire del optimismo de Leibniz. Y es que Leibniz ciertamente pensaba que habitamos el mejor de los mundos posibles, y ciertamente esta frase, sacada de su contexto original, puede parecer bastante ingenua. Tanto así que, al inicio del cuento de Voltaire, el mismo Cándido con toda razón se pregunta: "Si este es el mejor de los mundos imaginables, ¿cómo serán los otros?"

En este ensayo me gustaría evaluar tan optimista afirmación de Leibniz. I2 Evaluar dicha expresión significa, a mi entender, tratar de leerla a la luz del contexto original del cual se extrae dicha frase, es decir, adentrarnos aunque sea brevemente en el sistema que Leibniz formuló para rastrear los motivos que lo llevaron a expresarse de ese modo. En suma, lo que me interesa en este ensayo es tratar de encontrarle el sentido no solo a dicha frase, sino (en

\footnotetext{
' Voltaire, François Marie Arouet de, "Cándido o el optimismo", en: Cándido y otros cuentos, traducción de Antonio Espina, Madrid: Alianza Editorial, 1982, p. 65.
} 
contra de Voltaire quizá) al propio Leibniz mismo, o en todo caso, a su optimismo. Con eso en mente, vamos a empezar por plantear la tesis leibniziana de la multiplicidad de mundos posibles (I), para preguntarnos luego por qué, de entre ellos, nuestro mundo habría de ser el mejor, lo cual nos llevará a examinar el principio de razón suficiente (II). Al hacerlo nos toparemos inevitablemente con el tema de Dios, lo cual motivará a su vez la pregunta de por qué Dios eligió crear este mundo en particular en vez de otro (III). Finalmente vincularemos la armonía preestablecida con el optimismo.

\section{§1.}

Lo primero que hemos de notar cuando nos enfrentamos con una afirmación que dice que vivimos en el mejor de los mundos posibles, es que el nuestro es el mejor entre una multiplicidad de mundos posibles. En este sentido se expresa Leibniz en una carta a Louis Bourguet: "El universo es solamente la colección de una cierta clase de composibles, y el universo real es la colección de todos los posibles existentes (...) Y como hay diferentes combinaciones posibles, algunas mejores que otras, hay muchos universos posibles, cada uno de los cuales es una colección de composibles" ${ }^{2}$. Esta cita, que habla de universos posibles y universos reales, muestra la complicidad que hallamos en Leibniz entre lógica y ontología. Por un lado se habla de los distintos estatutos de lo que es (hay cosas, universos, posibles y cosas, universos, reales); por otro, se presenta una lógica combinatoria. Para poder entender adecuadamente esta cita voy, primero, a explorar el sistema lógico de Leibniz, pues es una cuestión tanto lógica como ontológica la que sustenta la creencia de Leibniz en la multiplicidad de mundos posibles ${ }^{3}$.

\footnotetext{
${ }^{2}$ Tomo la cita de: Copleston, Frederick, Historia de la filosofía. Volumen IV: De Descartes a Leibniz, traducción de Juan Carlos García-Borrón, Barcelona: Ariel, 198I, p. 262 (en la edición de Gerhardt de la obra de Leibniz la cita corresponde al volumen III de Die Philosophische Schriften von G.W. Leibniz, p. 573).

${ }^{3}$ Tradicionalmente se veía a Leibniz como un eminente metafísico, que había centrado sus preocupaciones en el tema de la sustancia. A comienzos del siglo $X X$, las investigaciones de Bertrand Russell y Louis Couturat sobre Leibniz inician una nueva corriente que insiste más en los temas lógicos de la obra de nuestro autor; según ellos, la metafísica leibniziana se deriva casi por completo de su lógica, y especialmente, de su teoría de la proposición (Cf. Sierra Mejía, Rubén, "Gottfried Wilhelm Leibniz", en: Tres textos metafisicos, traducción de Rubén Sierra Mejía, Bogotá: Norma, 1992, pp. 9; Cf. Parkinson, G.H.R., "La naturaleza de la proposición en Leibniz", en: ibid., p. 53). Sin embargo me parece que tanto en el Discurso de metafísica, texto temprano de Leibniz, como
} 
Leibniz separa las verdades en dos categorías: verdades de razón y verdades de hecho. Esta distinción es fundamental para él y está basada en la lógica de la proposición: toda proposición guarda la forma sujeto-predicado, y la verdad consiste en la correspondencia de una proposición con la realidad, pero la realidad, como veremos a continuación, puede ser posible o actual ${ }^{4}$. Detengámonos primero en las verdades de razón: "Hay dos especies de verdades: las de razón y las de hecho. Las verdades de razón son necesarias y su opuesto es imposible, y las de hecho son contingentes y su opuesto es posible. Cuando una verdad es necesaria, se puede encontrar su razón por medio del análisis, reduciéndola a ideas y a verdades más simples hasta llegar a las primitivas"5. Que una verdad sea de razón quiere decir lo siguiente: primero, que es necesaria puesto que su opuesto es imposible (de concebir, de componer; su opuesto, podríamos decir, es una no-cosa, algo que nunca podría ser verdadero). Es decir, no se puede negar una verdad de razón sin caer en contradicción. Por análisis podemos ir reduciendo las proposiciones de razón hasta llegar a las verdades más primitivas, conocidas por intuición, evidentes por sí mismas, y que Leibniz llama también "verdades idénticas" en el sentido de que no expresan nada nuevo del sujeto justamente porque expresan lo esencial, aquello sin lo cual un sujeto no podría ser sujeto (son, digamos, en sentido aristotélico, verdades o principios indemostrables, los primeros principios que concluyen una cadena analítica o inician una cadena demostrativa). En ese sentido, las verdades de razón corresponden a la esfera de la posibilidad: ellas indican lo que en todo caso podría ser verdad, lo que es necesario o indispensable para que algo sea verdadero, pero eso no quiere decir, en absoluto, que señalen lo que es verdad de hecho (para la esfera de la actualidad o existencia Leibniz reserva exclusivamente las verdades de hecho). Lo posible, entonces, no tiene por qué existir necesariamente de hecho,

en la Monadología, texto ya maduro, ambos ámbitos están de tal manera entrelazados, que resulta difícil decir cuál de ellos es el dominante. En este ensayo empiezo por la parte lógica simplemente por motivos de la exposición.

4 "Contentémonos con buscar la verdad en la correspondencia entre las proposiciones que hay en el espíritu y las cosas que se consideran (...) En un sentido exactamente igual podemos decir asimismo que un ser es verdadero, es decir, que la proposición que afirma su existencia actual o cuando menos su existencia posible es efectivamente una proposición verdadera" (Leibniz, G.W., Nuevos ensayos sobre el entendimiento humano (1704), edición de J. Echeverría Ezponda, Madrid: Editora Nacional, 1977, libro IV, cap. V, § I I, p. 477; en adelante: NE, seguido de número de libro, de capítulo, de parágrafo y de página). Cf. Copleston, Frederick, op. cit., p. 257.

${ }^{5}$ Leibniz, G.W., Monadología (I7I4), en: Tres textos metafísicos, § 33, p. 76 (en adelante: Monadología, seguido de número de parágrafo y de página). 
ya que lo único que lo define es que sea no-contradictorio: las verdades de razón se sustentan en el principio de identidad o no-contradicción ${ }^{6}$. De ahí que la distinción entre verdades de razón y verdades de hecho sea en Leibniz fundamental: ella delimita la esfera de lo posible y la esfera de lo actual.

La esfera de lo actual o de las verdades de hecho, como podemos ver, ocupa un pequeño espacio dentro de la esfera de la posibilidad. Las verdades de hecho están, por decirlo de algún modo, a otro nivel que las verdades de razón: por su naturaleza son proposiciones cuyo opuesto sí es concebible, y es posible negarlas sin entrar en contradicción lógica ${ }^{7}$. Ellas no son proposiciones necesarias sino solo contingentes, sus enunciados se refieren siempre (integran) al ámbito de lo existencial. El que las verdades de hecho sean proposiciones contingentes quiere decir que no podemos deducirlas a priori a partir de una verdad evidente por sí misma, es decir, que no son proposiciones "analizables" o reducibles como lo eran las verdades de razón, sino que conocemos su verdad a posteriori (por decirlo de algún modo, en el curso de la existencia). Con esto me parece que ya podemos empezar a entrever por qué Leibniz creía en la multiplicidad de universos: como la existencia no es un predicado necesario, el ámbito de lo actual bien pudo haber sido de otras maneras; $y$ todas esas posibilidades o modos en los que pudo haber sido el universo conviven en la esfera de lo posible. Hay, pues, diferentes mundos posibles ${ }^{8}$.

\footnotetext{
6 "Las verdades primitivas de razón son las que yo denomino con el apelativo de idénticas, porque parece que lo único que hacen es repetir lo mismo (...) Todo esto puede ser afirmado independientemente de cualquier prueba, o de reducirlo a la oposición o al principio de contradicción" (NE, IV, II, § I, pp. 434-435). Aquí, cuando Leibniz dice que las verdades primitivas de razón no necesitan de prueba, quiere decir que ellas no necesitan ser ejemplificadas por algún individuo particular para ser verdaderas. Un ejemplo clásico es el del triángulo: todo triángulo, sabemos, tiene por definición tres lados y la suma de sus ángulos internos es igual a la de dos ángulos rectos. Por más que no encontremos nunca un triángulo individual perfecto, no por ello la definición de triángulo deja de ser enteramente verdadera. Más bien es al revés: los individuos particulares tienen que "encajar" en los esquemas de las verdades de razón para existir.

${ }^{7}$ Cf. Copleston, Frederick, op. cit., p. 258. Por poner nuevamente un ejemplo clásico, nosotros estamos seguros de que el sol saldrá por las mañanas todos los días, pero es posible pensar sin entrar en contradicción que haya un día en que no salga el sol.

${ }^{8}$ Pongo aquí un ejemplo que extraigo de Copleston: en un sistema en el que por ejemplo $A$ tiene lugar, si B es lógicamente incompatible con A, B queda necesariamente excluido del sistema. Pero en otro sistema donde $B$ tuviera lugar, entonces sería $A$ quien necesariamente quedaría excluido (Cf. ibid., p. 262). La exclusión descansa en la lógica del sistema mismo, o en las relaciones de la serie, pero la afirmación de la existencia del sistema o de la serie misma no es necesaria: su contrario también es posible.
} 
Ahora que hemos establecido la multiplicidad de universos posibles, es momento de preguntarse, con Leibniz, qué motivos habría para que justamente exista un mundo tal cual nosotros lo conocemos. Si la existencia no es necesaria y pudo haber sido de cualquier otra manera (siempre que sea lógicamente posible), y si ninguna verdad de razón es capaz de establecerla, hace falta para Leibniz algún principio que motive el paso de la posibilidad a la actualidad. Leibniz lo llama principio de razón suficiente: como su nombre indica, es el principio que da razón de que algo sea más bien de un modo en vez que de otro. Como hemos visto, las verdades de razón se fundamentan en el principio de identidad o no-contradicción. Este principio no puede asimismo fundamentar las verdades de hecho porque en el ámbito de la contingencia las proposiciones admiten sus contrarios. Las verdades de hecho necesitan pues de otro principio que las rija, y este es justamente el principio de razón suficiente, "en virtud del cual consideramos que ningún hecho puede ser verdadero, o existente, ningún enunciado verdadero, sin que haya una razón suficiente para que sea de ese modo y no de otro"'. En otras palabras: nada sucede sin razón.

Según esto, no solo todo cuanto acontece en el mundo, sino el acontecer mismo del mundo, han de tener razones que los expliquen suficientemente. De ahí que para poder abordar la pregunta respecto de por qué nuestro mundo -el mundo existente- habría de ser el mejor posible, hemos de indagar pues en el principio leibniziano de razón suficiente.

\section{\$2.}

¿Por qué todo en el mundo habría de suceder de acuerdo a una razón? Hemos visto que en cuanto a la contingencia a se refiere, hay todo un abanico de posibilidades abierto; de ese abanico, solo una serie, entre muchas otras, entra en el curso de la existencia. No basta pues con que algo sea posible para que exista, ese algo requiere además de una razón suficiente. En el mundo de los hechos, puesto que toda existencia es contingente y todo podría ser de otra manera, nos topamos con una suerte de infinito. En lo que sigue voy a tratar de explicar mejor a qué me refiero con esto.

\footnotetext{
${ }^{9}$ Monadología, § 32, p. 76 (el énfasis es añadido).
} 
En los Nuevos ensayos sobre el entendimiento humano Leibniz se expresa de la siguiente manera: "Por paradójico que pueda parecer, nos resulta imposible tener un conocimiento de los individuos y encontrar exactamente el modo de determinar la individualidad de cada cosa (...) pues todas las circunstancias se pueden reproducir; las diferencias mínimas nos resultan insensibles; el lugar y el tiempo, lejos de ser ellos los que determinan por sí mismos, tienen más bien la necesidad de ser determinados por la cosa que contienen. Lo más notable en todo esto es que la individualidad implica el infinito, y solo quien puede comprender esto llegará a tener el conocimiento del principio de individuación de tal o cual cosa; lo cual se debe a la influencia (bien entendida) de todas las cosas del universo unas sobre otras"|0. Esta larga y quizá oscura cita que acabo de colocar nos ofrece la oportunidad de decir muchas cosas; veamos por un momento algunas de ellas. En primer lugar, cuando Leibniz dice que, por paradójico que parezca (porque justamente lo que nos parece más cercano son los individuos concretos), nos es imposible tener conocimiento de los individuos, a lo que se refiere es a que un individuo no es simplemente un "momento de un individuo". Es decir, tener en algún momento cierto conocimiento "puntual” respecto de algún individuo no determina plenamente a ese individuo. Para poder determinar su individualidad habría que conocer toda su historia, tener a la vista de un tirón todo el curso de sus acontecimientos, de todas sus complejidades. Incluso, nos dice Leibniz, si por ejemplo congelásemos al individuo en un espacio y un tiempo determinado, no seríamos capaces de percibir todas las múltiples y mínimas cosas que se mueven en su interior ( $y$ es por ello que espacio y tiempo no son criterios suficientes para determinar al individuo, sino a la inversa, ellos son determinados por él). Cuando se habla aquí de infinito estoy entendiendo, pues, este ámbito de múltiples posibilidades de las que el individuo es capaz, aunque no sean (no puedan ser) todas ellas realizadas. Lo que se quiere decir con esto, a mi entender, es que el individuo es de tal manera inabarcable que no basta simplemente con una mera afirmación o enunciación de lo que el individuo es para determinarlo por completo; el individuo es bastante más complejo que eso. En él están pues latentes infinidad de posibilidades, de cambios, $y$ en ese sentido se puede decir que el individuo o lo individual implica el infinito.

${ }^{10} \mathrm{NE}$, III, III, § 6, p. 34I (el énfasis es añadido). 
El tema del individuo como infinito me parece que es de suma importancia en la filosofía de Leibniz y que tiene que ver básicamente con la concepción leibniziana de la sustancia individual. La noción de sustancia individual, dice Leibniz en su Discurso de metafísica, "encierra de una vez todo lo que le puede suceder y cuando se considera esta noción, puede verse allí todo lo que se podrá enunciar de ella de manera verdadera""I. Según esta cita, la noción de sustancia individual guarda en su seno toda la gama de posibilidades que puede eventualmente realizar. En el caso de un individuo concreto, su origen en la existencia ha puesto en curso una serie de combinaciones posibles. Sin embargo, al ser ese individuo concreto una sustancia individual, sigue conteniendo, pues, el infinito en su interior. Quisiera hacer notar aquí que una de las cosas que me parece le está interesando resaltar a Leibniz es que la determinación de un individuo no puede hacerse desde afuera, no puede hacerse con criterios extrínsecos al individuo mismo. De ahí creo que procede su insistencia en que incluso todos los predicados contingentes (lo que le puede suceder) están ya contenidos desde un inicio en el sujeto (en la sustancia individual) $)^{12}$. $Y$ es que si el individuo se determinara por razones externas a su naturaleza, la sustancia no sería otra cosa que algo inerte, carente de vida, "pura máquina". Volveremos sobre esto más adelante.

Todos los posibles predicados contingentes están entonces contenidos en la noción de sujeto, pero para que uno de ellos entre en acción hace falta pues de algo que lo mueva, que lo invite a realizarse. Si nos quedamos solamente con el principio de razón suficiente, sabemos que todo sucede de acuerdo a una razón, pero no podemos aún entender por qué ha de ponerse en movimiento un curso de acción en vez de otro. Esto sugiere que el principio de razón suficiente parece quedar huérfano, estéril, sino no se lo acompaña de algo más. En otra carta a Bourguet, Leibniz dice lo siguiente: "Hay una diferencia

\footnotetext{
"Leibniz, G.W., Discurso de metafísica ( I685), en: Tres textos metafísicos, § I3, p. 24 (en adelante: Discurso, seguido de número de parágrafo y de página). En este parágrafo se encuentra el tradicional ejemplo de Leibniz sobre la resolución de Julio César de cruzar el Rubicón. Leibniz se da cuenta que lo que está proponiendo respecto de la sustancia individual parece destruir la libertad humana, y para demostrar que no es así utiliza este ejemplo tantas veces comentado. Sobre él y el tema de la libertad volveremos más adelante.

12 Por ello dice Copleston que una de las cosas que se desprenden del principio de razón suficiente es que todas las proposiciones contingentes, al igual que las proposiciones necesarias, son analíticas. La diferencia estaría en que solo las segundas son "finitamente" analíticas (Cf. Copleston, Frederick, op. cit., p. 264).
} 
entre el análisis de lo necesario y el análisis de lo contingente. El análisis de lo necesario, que es análisis de esencias, va de lo que es posterior por naturaleza a lo que es anterior por naturaleza, y termina en nociones primitivas, y es así como los números son resueltos en unidades. Pero en los contingentes o existentes, ese análisis de lo subsiguiente por naturaleza a lo anterior por naturaleza procede hasta el infinito, sin que sea nunca posible una reducción a elementos primitivos"'3. Cuando hacemos el análisis de lo necesario, que se basa en el principio de identidad o no-contradicción, nos dice Leibniz aquí que partimos de lo que es esencialmente posterior, pero más cercano a nosotros, a nuestra experiencia, para llegar a lo que es esencialmente anterior: las nociones primitivas (como el tema de la unidad o la identidad) sin las cuales no sería siquiera posible nuestra experiencia. En el caso de lo contingente, ese análisis no es del todo posible porque dicho proceso no tiene fin, cayendo, en buena cuenta, en un regresus ad infinitum. Contemplamos por ejemplo que del rosal de nuestro jardín ha nacido una flor y tratamos de analizar los orígenes de dicha rosa; vemos que antes de que hubiera flor había una planta; antes de que creciera la planta habíamos plantado una semilla y esa semilla había germinado gracias a la acción del agua sobre la tierra; pero a su vez esa semilla había brotado de algún otro rosal, etc. Lo mismo sucede si analizamos una acción humana particular: si buscamos hacia atrás las razones o causas de una acción individual, podremos siempre hallar causas anteriores sin llegar nunca a un fin del proceso. Esto tiene que ver ciertamente con el principio de razón suficiente; en buena cuenta, el principio de razón suficiente, al señalar que nada sucede sin razón, es en el fondo el principio de causalidad, con la única salvedad de que en el caso de Leibniz (no así para la mayoría de modernos) la causalidad no conlleva necesidad. Si a cada efecto corresponde una causa, y dicha causa es a su vez efecto de una causa anterior, entonces el principio de razón de suficiente nos lleva, obligatoriamente, a un círculo. Y me parece a mí que es correcto que esto sea así. Voy a explicar ahora por qué.

Si volvemos a la cita de los Nuevos ensayos que coloqué ya varios párrafos arriba, podemos ver que, en segundo lugar, Leibniz habla de una "influencia de todas las cosas del universo unas sobre otras". El universo es pues de algún

\footnotetext{
${ }^{13}$ Esta cita también la extraigo de Copleston en: ibid., p. 264 (en la edición de Gerhardt, corresponde al volumen III, p. 582). Dicho de paso, esta cita ciertamente hace acordar a aquella distinción aristotélica entre el orden del ser y el orden conocimiento.
} 
modo un círculo, en el sentido en que sus partes o elementos integrantes están siempre en comunicación o interrelacionadas y guardan en ese sentido una cierta regularidad o armonía: todo sucede por alguna razón. Recordemos que para Leibniz "el universo es solamente la colección de cierta clase de composibles", y, como hemos visto, esa "composibilidad" tiene que ver con la lógica de las relaciones que se establece al interior de un sistema. Con esto quiero decir que el mundo, mundo de los hechos, el mundo regido por la razón suficiente, es pues para Leibniz un sistema, pero un sistema en este sentido "circular" que estoy tratando de darle al término: al interior de él, no hay propiamente ni comienzo ni fin, pues, en el más pleno sentido heracliteano, en él todo fluye ${ }^{14}$. Si no fuera así, podríamos decir que los acontecimientos del mundo ocurrirían de modo azaroso: no habría ninguna regularidad en la naturaleza (no podrían construirse las ciencias naturales), no se podrían imputar motivos a las acciones humanas (no habría disciplinas como el derecho o la jurisprudencia).

Sin embargo todavía no se explica por qué ha de ponerse en marcha un curso de acción en vez de otro, por qué se inicia una serie de combinaciones en particular, en fin, por qué se pone en movimiento un mundo (el mejor de los mundos posibles, además) en vez de cualquier otro. El que esta cuestión quede aún indeterminada tiene que ver con que en Leibniz el principio de razón suficiente no sea necesario, quedando entonces suelta justamente la cuestión respecto de por qué existen unos seres en vez de otros. Esta cuestión nos invita, casi nos obliga, a pensar en alguna finalidad, a introducir una teleología que justifique la existencia del mundo real, que rescate al mundo actual del universo infinito de mundos posibles. La otra cara que complementa el principio de razón suficiente, que garantiza que el mundo se despliegue "lo mejor posible”, es esta causalidad final o noción teleológica del bien. Para decirlo brevemente e introducir de una vez un elemento primordial en el pensamiento leibniziano, esta finalidad, que siendo causa final es a la vez principio, es Dios: “(...) es necesario que la razón suficiente o última esté fuera de la serie o series de ese detalle de las contingencias, por infinito que pudiera ser. [§ 38] Y es así como la razón última de las cosas debe encontrarse en una substancia

14 "Pues todos los cuerpos, como los ríos, están en un flujo perpetuo, y las partes entran y salen continuamente de ellos" (Monadología, § 7।, p. 85). 
necesaria, en la cual el detalle de los cambios solo esté de modo eminente, como en la fuente: y es esto a lo que llamamos Dios”|5. Dios es el único ser cuya mera posibilidad implica su existencia; la única proposición existencial que es estrictamente necesaria es la que afirma la existencia de Dios. Dios es pues la causa incausada, la única sustancia existente estrictamente necesaria que, como fuente de la que emana el río que luego sigue su curso a través de valles, montañas, etc., es origen, razón suficiente, del mundo actual.

\section{§3.}

Ahora bien, si Dios, como la "sustancia suprema", ha establecido por un lado que el mundo existente sea el mejor posible, eso no explica, por otro lado, por qué Dios eligió justamente este mundo en particular. Leibniz no se conforma con responder simplemente que Dios así lo quiso; esa respuesta haría del acto de creación de Dios un acto meramente arbitrario. Siendo Dios el ser absolutamente perfecto, decir que sus obras dependen de su capricho equivale a poner a límite a un ser que por definición carece de ellos ${ }^{16}$. La voluntad de Dios está regulada y actúa en conformidad con el entendimiento divino. Es decir, que Dios no hace nada en contra de la razón ${ }^{17}$. Las obras de Dios son loables no simplemente porque hayan sido hechas por él, sino porque, siendo el ser absolutamente perfecto, Dios no hace nada sin tener alguna razón igualmente perfecta que mueva a su voluntad a elegir algo en vez de otra cosa. El Dios del que estamos hablando aquí, el Dios de la metafísica de Leibniz, es un Dios enteramente racional, podría decirse, es la razón suprema, la racionalidad última.

La creación ha sido pues elección divina, pero esta elección tiene también una razón de ser suficiente ${ }^{18}$. Esta razón se encuentra en el principio teleológico

\footnotetext{
${ }^{15}$ Ibid., §§ 37-38, p. 77 (el énfasis es añadido). Cf. Copleston, Frederick, op. cit., p. 265.

16 "Esta Substancia Suprema, que es única, universal y necesaria, al no existir nada fuera de ella que sea independiente, $y$ que es sencillamente una consecuencia del ser posible, debe carecer de límites y contener toda la realidad posible. [§ 4I] De donde se sigue que Dios es absolutamente perfecto (...) y donde no hay límites, es decir, en Dios, la perfección es absolutamente infinita" (Monadología, §§ 40-4I, p. 77).

${ }^{17} \mathrm{Cf}$. Discurso, §§ I-3, pp. 9-I2.

18 “ (...) era razonable y por consiguiente seguro que esto sucediese, pero no porque sea necesario en sí mismo ni lo contrario implique contradicción” (ibid., § I3, p. 26).
} 
que Leibniz ha introducido en su sistema: Dios, como racionalidad última, elige siempre y de manera cierta, aunque libremente, lo objetiva o racionalmente mejor: “(...) todas las proposiciones contingentes tienen razones para ser de esta manera y no de otra. $\mathrm{O}$ bien (lo que es lo mismo), poseen pruebas a priori de la verdad que las hace ciertas y muestran que la conexión del sujeto y el predicado de esas proposiciones tienen su fundamento en la naturaleza del uno y del otro; pero no disponen de demostraciones de necesidad, puesto que estas razones no están fundadas más que en el principio de la contingencia o de la existencia de las cosas, es decir, en aquello que es o parece ser lo mejor entre varias cosas igualmente posibles"'19. En este sentido, la creación no es absolutamente necesaria, pero si Dios crea, entonces crea el mejor de los mundos posibles. Dios es así el principio de la contingencia.

Plantear las cosas de esta manera, presentar a un Dios que tiene conocimiento a priori de todos los sucesos del mundo, parece entrar en conflicto con la libertad individual. Para salvar el optimismo de Leibniz de la "predestinación" - "predeterminación" a la que parece abandonarse con el postulado de un Dios enteramente racional, hemos de tratar de entender en qué sentido Leibniz concilia ambos. Lo haremos tocando primero nuevamente el tema de la sustancia individual, y segundo vinculando a esta con la hipótesis de la armonía preestablecida.

Hemos visto que la sustancia es, pues, un sujeto que contiene virtualmente todos los predicados que puede tener. Habíamos dicho también que si la sustancia individual se determinara por causas exteriores, ella no sería más que algo inerte. Ahora nos toca examinar brevemente por qué. Una sustancia no podría desarrollar sus propias potencialidades, es decir, no podría pasar de un estado a otro sin dejar de ser el mismo sujeto, si no fuera porque posee un 22 principio interno que tiende hacia su propio auto-despliegue. Esta tendencia interna al auto-despliegue es lo que hace de la sustancia un ser esencialmente activo; cada sustancia es principio y fuente de sus actividades: "Se les podría dar el nombre de entelequias a todas las substancias simples, o mónadas creadas, pues ellas tienen en sí cierta perfección y una suficiencia que las convierte en fuente de sus acciones internas y, por así decirlo, autómatas

${ }_{19}^{19}$ bid., § I3, p. 27 (el énfasis es añadido). Cf. Copleston, Frederick, op. cit., p. 268. 
incorpóreos" 20 . De ahí que fuerza y energía sean características esenciales suyas. Es en virtud de esta actividad auto-desplegante propia de la sustancia que podemos afirmar, ahora sí, que la sustancia no podría ser nunca algo material, inerte, carente de vida. Esta actividad o vida interior de la sustancia nos confirma que ella es en última instancia espiritual. En un muy metafórico pasaje de la Monadología, Leibniz habla de esta vida sustancial de la materia de la siguiente forma: "Cada porción de la materia puede ser concebida como un jardín lleno de plantas y como un estanque lleno de peces. Pero cada rama de la planta, cada miembro del animal, cada gota de sus humores es también un jardín o un estanque semejante. [§ 69] Así, nada hay inculto, estéril, muerto en el universo (...)"21. De este modo nos presenta Leibniz al universo como un organismo vivo, como un cuerpo orgánico, que atraviesa y complementa el mundo mecánico de los fenómenos. Solo en un nivel fenoménico puede hablarse de mecanicismo, de causalidad a secas; metafísicamente no puede más que hablarse de armonía ${ }^{22}$ : "Estos principios me han permitido explicar de manera natural la unión o bien la conformidad del alma con el cuerpo orgánico. El alma sigue sus propias leyes y el cuerpo las suyas; se encuentran en virtud de la armonía preestablecida entre las sustancias, puesto que todas ellas son representaciones de un mismo universo" 23 .

¿Qué sucede con la libertad individual humana, moral? ¿Son las acciones de los hombres actos libres o han sido predeterminados? Para responder a esta

\footnotetext{
${ }^{20}$ Monadología, § I8, p. 72. Cf. Copleston, Frederick, op. cit., pp. 272, 280.

${ }^{21}$ Monadología, §§ 67, 69, pp. 84, 85.

${ }^{22}$ Cf. Valentie, María Eugenia, Una metafísica del hombre. Ensayo sobre la filosofía de Leibniz, Tucumán: Instituto de Filosofía de la Universidad de Tucumán, 1956, p. 65. Armonía, finalmente, entre mecanicismo y espiritualismo. Leibniz todo el tiempo está tratando de conciliar ambas. Por un lado vemos, corroboramos constantemente que en el mundo material las cosas funcionan con una cierta regularidad bastante estable que corresponde al principio de causalidad. Sin embargo, al tratar de penetrar en la materia para explicar su subsistencia nos damos cuenta que la materia no puede explicarse por sí misma. Hay ahí incluido un elemento espiritual, vital, que muchos filósofos modernos han tratado forzosamente de desoír. El tema está, creo yo, justamente en la armonía: Leibniz no trata de desprestigiar el principio físico-matemático moderno de la causalidad, pero tampoco rechaza la noción teleológica de sustancia de los antiguos y escolásticos. Más bien su sistema busca conciliar ambas nociones o principios de una manera armónica, de forma tal que se muestre su mutua cooperación. A este respecto me llaman la atención las metáforas que utiliza Leibniz al referirse al cuerpo orgánico o ser vivo como "especie de máquina divina, o de autómata natural, que supera infinitamente a todos los autómatas artificiales" (Monadología, $\S 64$, p. 83).

${ }^{23}$ Ibid., § 78, p. 87 (el énfasis es añadido).
} 
última cuestión vamos a traer aquí el ejemplo de Julio César que antes hemos mencionado. Julio César llegó a ser dictador perpetuo y amo de la República, y destruyó la libertad de los romanos. ¿Debemos entender que estas acciones fueron predeterminadas debido a que estaban contenidas de antemano en la noción de Julio César? Mi respuesta sería que no: siempre cabe la posibilidad de que Julio César haya obrado de manera distinta. El único que tiene conocimiento a priori de que Julio César actuaría de todos modos de esa manera es Dios, pero nosotros no tenemos la visión omnisciente de Dios, y en ese sentido no nos queda más que transcurrir por el curso de la historia, pasar nosotros mismos por la distintas experiencias a las que nos veremos sometidos, tomar decisiones por nuestra cuenta, para llegar tan solo a raspar muy superficialmente algo similar al conocimiento divino. En el mismo sentido, en otra parte del Discurso de metafísica, Leibniz se pregunta: "iPor qué Judas, el traidor, que solo es posible en la idea de Dios, existe realmente?”. Esta nueva formulación del problema parece bastante más fina que la anterior, porque lo que se está preguntando aquí es por qué Dios, entonces, admite el mal. Leibniz responde de esta manera: "a esta pregunta no hay respuesta que podamos esperar aquí abajo, y solo puede decirse en general que puesto que Dios ha encontrado conveniente que él exista, no obstante el pecado que él preveía (...) se hallará que esta serie de cosas en la cual está comprendida la existencia de este pecador es la más perfecta entre todas las otras maneras posibles" ${ }^{24}$. El tema aquí es que Dios, siendo justamente omnisciente, sabe que si interviniera en el curso de la historia malograría la perfección de su obra. Como hemos ido viendo, Dios ha creado el mundo de tal manera (la mejor posible), que él tiene toda la capacidad de auto-desarrollarse hasta el infinito. Si Dios interviniera, recortaría la libertad. De ahí que Dios no sea causante del mal (de él responsables somos nosotros), sino solo creador de la libertad.

24 Esta libertad humana o moral Leibniz parece situarla en un plano distinto. En los últimos parágrafos de la Monadología, cuando Leibniz llega al tema de los espíritus, de repente introduce un nuevo vocabulario: allí donde hablaba de Dios como del inventor de una máquina propia (o como gran geómetra, o como gran arquitecto) en cuanto a su relación con las cosas del mundo, en cuanto a su relación con los espíritus, Dios es, además, como un príncipe

${ }^{24}$ Discurso, §30, p. 56. 
es con sus súbditos e incluso como un padre es con sus hijos. Esto hace que "los espíritus (o almas racionales) sean capaces de entrar en una especie de sociedad con Dios (...) [§ 85] constituir la ciudad de Dios"25. Cuando digo que parece hablar aquí de un plano distinto no me refiero a que se establezca un nivel absolutamente diferenciado y ajeno al universo orgánico del que hemos venido hablando, sino más bien a que este plano en el que solo los espíritus entran en comunidad con Dios constituye el nivel más elevado que puede alcanzar la sustancia individual ${ }^{26}$. Ciertamente, aún en el nivel superior, la armonía universal sigue garantizando la interrelación entre los distintos planos que componen la complejidad del mundo: "Así como establecimos una armonía perfecta entre dos reinos naturales, el de las causas eficientes y el de las finales, aquí debemos llamar la atención también sobre otra armonía existente entre el reino físico de la naturaleza y el reino moral de la gracia (...) [§ 88] Esta armonía hace que las cosas conduzcan a la gracia por las vías mismas de la naturaleza" ${ }^{27}$.

Nuevamente, lo que me interesa destacar, ya para cerrar el desarrollo de este ensayo, es que para mí la idea fundamental en la filosofía de Leibniz es probablemente la de "la armonía universal del sistema potencialmente infinito de la naturaleza"28: "Y si el primer principio de la existencia del mundo físico es el decreto de darle la mayor perfección posible, el primer designio del mundo moral, o de la ciudad de Dios, que es la parte más noble del universo, debe ser expandir la mayor felicidad posible"29.

Para finalizar quisiera decir solo una cosa más. Creo que si miramos en detalle $y$, sobre todo, tratando de encontrarle sentido a los argumentos ofrecidos por Leibniz para afirmar que vivimos en el mejor de los mundos posibles (en vez de quedarnos simplemente con la afirmación gruesa), hemos de reconocer que el sistema de Leibniz es consistente y dicha tesis se sostiene. Por supuesto esto solo es aceptable si admitimos ciertos presupuestos de los que Leibniz

\footnotetext{
${ }^{25}$ Monadología, §§ 84-85, p. 88.

26 "Esta ciudad de Dios, esta monarquía verdaderamente universal, es un mundo moral en el mundo natural, y lo más elevado y lo más divino en las obras de Dios” (ibid., § 86, p. 88).

${ }^{27}$ lbid., §§ 87-88, p. 89.

${ }^{28}$ Tomo prestada esta expresión de Copleston, Frederick, op. cit., p. 276.

${ }^{29}$ Discurso, §36, p. 67.
} 
parte, como, por ejemplo, el presupuesto básico de que todo cuanto ocurre en el mundo sucede de acuerdo a una razón suficiente. Este presupuesto, no obstante, no podemos achacárselo exclusivamente a Leibniz, pues si bien él fue uno de los que lo formuló de manera más expresa, es un presupuesto compartido por (casi podríamos decir propio de) toda la modernidad ${ }^{30}$. En ese sentido, me parece que si nos preguntamos respecto del por qué o la razón de la creencia radical de Leibniz en el principio de razón suficiente, hemos pues de tener en cuenta que aquel (el presupuesto matemático), era el presupuesto privilegiado de aquellos momentos y que andaba al compás de la época. Nada de esto hace del sistema de Leibniz, a mi entender, un sistema menos consistente, siempre y cuando tengamos en cuenta que pedir explicaciones absolutas es, ayer, hoy y muy probablemente siempre, imposible, y hoy en día además irrelevante. El sistema de Leibniz ciertamente presenta complejidades e incluso contradicciones difíciles de abordar, pero creo que el mérito consiste más en acoger y tratar de convivir "armónicamente" con las complejidades y contradicciones (de las cuales será muy difícil alguna vez liberarnos) en vez de hacerlas a un lado en vistas de la distinción y claridad. En suma, allá uno si cree en el optimismo de Leibniz o no, pero Leibniz, en todo caso, tiene sus razones para afirmar que vivimos en el mejor de los mundos posibles y más aún para creerlo.

\footnotetext{
${ }^{30}$ Holzapfel tiene al respecto un ejemplo bastante simpático que me gustaría incluir aquí; resumo: Camino por la calle vacía un domingo, en eso recuerdo que un amigo que no veo hace mucho vive por aquí y decido darle una visita sorpresa, sin embargo no recuerdo exactamente el número de su casa, así que toco la puerta de un vecino con la intención de preguntar. "Una señora abre la puerta y se adelanta muy cautelosa hasta el portón. Ya en su cara seria y preocupada se desdibuja un estar dominada por las razones que expliquen suficientemente: iquién soy?, iqué quiero?, ipor qué toco el timbre de su casa?, isoy confiable? Ahora bien, yo mismo y el hombre moderno somos como esta señora, y existimos en todo momento en el mundo de la razón suficiente de por qué esto y lo demás, sin que nada pueda escapar a ello" (Holzapfel, Cristóbal, Crítica de la razón lúdica, Madrid: Trotta, 2003, p. II).
} 